\title{
Inactivation du gène Xist : encore beaucoup de questions à résoudre
}

médecine/sciences a suivi de près l'histoire de l'inactivation du chromosome $\mathrm{X}$ et d'un de ses acteurs principaux: le gène Xist. Ainsi, nous rapportions l'an passé que l'invalidation du gène Xist dans une lignée de cellules ES aboutissait à une inactivation systématique du chromosome $\mathrm{X}$ n'ayant pas subi la mutation, prouvant ainsi que le gène Xist est indispensable au processus d'inactivation $\left(\mathrm{m} / \mathrm{s} n^{\circ} 3\right.$, vol. $\left.12, p .409\right)$. Ce gène indispensable ne code pour aucun produit protéique et c'est le transcrit lui-même qui est probablement impliqué dans l'inactivation. Un autre exemple de ce type est celui du transcrit $H 19$ qui est à l'origine de l'extinction des gènes $\operatorname{Ig} f 2$ et Ins-2, tous deux soumis à empreinte parentale $[1,2]$. Cependant, le rôle précis du transcrit Xist dans ce phénomène reste encore mystérieux. Les travaux récemment publiés par l'équipe de R. Jaenisch (Cambridge, MA, USA) apportent une pierre supplémentaire à l'édifice [3]. Ces auteurs ont en effet utilisé la même approche de recombinaison homologue et ont ainsi obtenu des souris invalidées pour le gène Xist sur un chromosome $\mathrm{X}$. Les premiers résultats obtenus sont les suivants: les mâles mutants sont normaux et fertiles. Les femelles hétérozygotes qui ont hérité de la mutation de leur mère sont également normales mais celles qui l'ont hérité de leur père meurent précocement au cours de l'embryogenèse. Dès 6,5 jours de développement embryonnaire la taille de ces dernières est anormalement réduite et ce retard de croissance s'aggrave entre 6,5 jours et 10,5 jours, date à laquelle la plupart des embryons régressent. L'analyse du trophoblaste de ces femelles révèle que les gènes portés par chacun des deux chromosomes X sont exprimés. Rappelons en effet que, dans les tissus extraembryonnaires murins ou humains, l'inactivation n'a pas lieu au hasard, comme dans les tissus constituant l'embryon, mais qu'elle touche systématiquement le chromosome $\mathrm{X}$ paternel. Ce dernier étant muté chez les femelles Xp Xist- Xm, il ne peut subir le processus d'inactivation et les 2 X restent actifs. En revanche, des souris XO dont le chromosome X unique, hérité du père, porte l'allèle Xist invalidé, présentent un développement embryonnaire a priori normal. Par conséquent, la létalité des femelles XX ayant elles aussi hérité de la mutation de leur père est probablement due à l'incapacité des tissus extra-embryonnaires dont les $2 \mathrm{X}$ sont actifs, d'assurer leur fontion essentielle à la survie de l'embryon. En outre, l'activation normale de l'X maternel chez ces animaux montre que l'absence de l'ARN Xist n'empêche pas la distinction entre $\mathrm{X}$ maternel et paternel, mais seulement l'inactivation de ce dernier.

Par ailleurs, ces résultats indiquent que le gène Xist n'est pas requis pour la spermatogenèse et n'est donc surement pas impliqué dans la condensation de l'X au cours de la prophase de la première division méiotique des spermatogonies.

Chez les embryons femelles hétérozygotes pour la mutation, l'inactivation ne se fait plus au hasard mais touche systématiquement l'X normal. L'hypothèse la plus probable pour expliquer ce phénomène est qu'il existe, au moment de l'inactivation, des cellules portant soit un $\mathrm{X}$ actif (par inactivation de l'X normal) soit deux $\mathrm{X}$ actifs (par impossibilité d'inactiver l'X muté) mais que, par la suite, ces dernières sont contre-sélectionnées du fait du déséquilibre génique. Cette hypothèse mérite d'être confirmée et confrontée à la seconde hypothèse qui suppose d'abord le choix d'un des chromosomes X pour l'inactivation puis, s'il s'agit du chromosome $\mathrm{X}$ ayant inactivé le gène Xist, la réorientation du choix dans un second temps vers l'X normal.

$\mathrm{Si}$ ces résultats sont intéressants, ils sont encore loin de lever le mystère de l'inactivation: ces observations sont-elles spécifiques de la souris ou sont-elles applicables à l'espèce humaine? Comment l'ARN Xist est-il capable de reconnaîre spécifiquement le chromosome qui l'exprime ? Une fois reconnu, quels sont les mécanismes aboutissant à l'inactivation transcriptionnelle des gènes portés par ce chromosome? Quel serait le phénotype d'un embryon femelle homozygote pour la mutation Xist au niveau des tissus embryonnaires, mais protégé de la létalité due à la mutation dans les tissus extra-embryonnaires, par exemple par fusion avec une morula tétraploïde non mutée? Des questions qui feront probablement l'objet de nouvelles élégantes démarches scientifiques et ipso facto de discussions dans ces colonnes!

H.G.

1. Leighton PA, Ingram RS, Eggenschwiller J, Efstratiadis A, Tilghman SM. Disruption of imprinting caused by deletion of the $\mathrm{H} 19$ gene region in mice. Nature $1995 ; 375: 34-9$.

2. Dandolo L. Empreinte parentale des gènes H19 et IGF-2. Med Sci $1995 ; 11: 1483-6$.

3. Marahrens Y, Panning B, Dausman J, Strauss W, Jaenisch R. Xist-deficient mice are defective in dosage compensation but not spermatogenesis. Genes Dev 1997 ; 11 : 156-66. 